\title{
Prediction Models for Total Customer Satisfaction Based on the ISO/IEC9126 System Quality Model
}

\author{
Kazuhiro Esaki \\ Faculty of Science and Engineering, HOSEI University, Tokyo, Japan \\ Email: Kees959@hotmail.com
}

Received March 14, 2013; revised April 14, 2013; accepted April 21, 2013

Copyright (C) 2013 Kazuhiro Esaki. This is an open access article distributed under the Creative Commons Attribution License, which permits unrestricted use, distribution, and reproduction in any medium, provided the original work is properly cited.

\begin{abstract}
The profitability of the system product is decided on the sales of the product. Furthermore, a customer satisfaction for products quality and a price have a big influence on the sales of the product. It spends limited financial resources effectively to raise the profitability of the system product, and it is necessary to realize the high quality product correspond to the customer needs as much as possible. There may be close relationship between cost of a product and an expense to implement the individual inherent attribute of system product. For the purpose of improvement of the customer satisfaction for quality of system product, the method of quantitative quality requirement and evaluation based on the ISO/IEC9126 quality model that includes six quality characteristics is widely recognized. However, independency among each quality characteristic has not been sure and the suitability of method for quality requirement of system product by using these six quality characteristics could not certified statistically. In the precedent study, introduced the requirements definition method for the quality of system product based on the system quality model defined in ISO/IEC9126 and proposed the effectiveness of it statistically. This study have measured the customer satisfaction for the system quality from the viewpoint of six quality characteristics quantitatively and confirmed the effectiveness of the technique to evaluate. In this study, we have confirmed the relationship between inherent attributes of the product and quantitative result of a measured value of total customer satisfaction from the view point of six quality characteristics statistically. This study performed the trial to clarify the relations with the inherent attributes that quantitative result of a measurement of the customer satisfaction based on six quality characteristics by the quality model of ISO/IEC9126. In addition, this study performed the development of the prediction model to estimate the total customer satisfaction for the system product from the view point of inherent attribute of the product. In this paper, we propose the effectiveness of application of the estimated prediction model and possibility of improvement of the total customer satisfaction of a system product.
\end{abstract}

Keywords: System; Software; Quality Requirement; Quality Evaluation; Quality Model; Quality Characteristic; Inherent Attribute; Quality Measure; Prediction Model; Total Customer Satisfaction

\section{Introduction}

The profitability of system product is decided by sales of products influenced by a price and an inherent attribute of product. Furthermore, a customer satisfaction and price of product have a big influence on sales of a product. Furthermore, a customer satisfaction and a price of product have a big influence to sales of a product. In order to improve customer satisfaction of system product successfully, it is very important to catch-up the customer's quality needs and high quality products should be designed corresponding to the real customer needs during possible early stage of development.

From the view point of expected profitability, financial resources should be limited and the most suitable product should be realized from the view point of customer need and based on the consideration of reduction of cost.

But it is necessary to realize attractive and coseffective product correspond to the real customer needs as much as possible. Usually, relationship between sales and customer satisfaction, which is caused by the inherent quality of product, may be recognized closely.

In order to realize suitable quality of product, it is necessary to grasp the quality requirement of customers for a system accurately, and the quantitative and concrete inherent quality for targets system product should be defined. After that, requirement of inherent attributes should be described into the quality requirement specifi- 
cation. If we take the wrong approach to requirement specification based on the real needs of quality of system product, it may cause a big loss for a purpose of invest- ment.

In recent years, we have been working on developing the ISO/IEC25000 (SQuaRE) series [1-5] of standards for quality requirements and evaluation for system and software product for a long time in ISO/IEC JTC1 (Joint Technical Committee 1 of the International Organization for Standardization and the International Electro technical Commission) SC7WG 6 (software and systems engineering under ISO technical committee, working group six). As part of this project, we have also worked on the developments of ISO/IEC9126-1 [6] (This standard has revised to ISO/IEC25010:2011 [5]), which are the standards to provide supporting technology for above mentioned works and also we have developed the quality characteristics.

Currently, the method of quantitative quality requirement definitions [2,7] based on ISO/IEC9126-1 [6] quality model is widely recognized and used in worldwide for the purpose of specify the quality requirement and evaluation of system/software product. ISO/IEC-9126-1 defines the six quality characteristics of the system and software. These six quality characteristics are described based on the model of Boehm [8] or McCall [9], or from the view point of a stakeholder's wide experience, which are considered as necessary and de pendent from customer's point of view. This model introduced in ISO/ IEC9126-1 may be formulated with almost perfect quality target establishment and evaluation perspective of the system. Through analyzing customer requirements based on these six quality characteristics, it becomes possible to perform complete and objective evaluation of customer quality requirements for a system/ software product. Although a certain level of improvement is expected in the completeness of describing product quality objectives by using the ISO/IEC9126-1 quality model.

However, for an evaluation of the customer satisfaction about the system quality, the effectiveness of the quality model application was not inspected because independency of each quality characteristic is not sure and the suitability of method by using these six quality characteristics for quality requirement and evaluation is not certified statistically.

In recent years, customers are now able to purchase products based on an increasing number of customer reviews posted on the Internet web site. For example, an online negative review may relate to a serious concern that affects the operation of the laptop computer, or it may relate to a relatively minor concern that does not affect the operation of the system, but expresses personally preference. Therefore, the degree of customer dissatisfaction may not be accurately obtained by simply classifying online negative reviews into the six quality characteristics. This study focuses on negative reviews of
Laptop Personal Computers (LPCs) posted by consumers and this study uses the statistical analysis approach based on the previous study of software product and process improvement $[10,11]$.

Above assumption, we tried to verify the validity and effectiveness of quantitative quality requirement definition from the view point of six quality characteristics andinspected requirements definition of the system quality based on the system quality model of ISO/IEC9126, and the effectiveness of the evaluation in the precedent study statistically, measured the customer satisfaction for the system quality from the viewpoint of six quality characteristics quantitatively and confirmed the effectiveness of the technique to evaluate.

Based on the result of previous study, this study performed the trial to clarify the relations with the inherent attributes of product and quantitative result of a measurement of the customer satisfaction based on six quality characteristics defined by the quality model of ISO/ IEC9126. In addition, this study performed development of the prediction model to estimate the total customer satisfaction for the system product from the view point of inherent attribute of product. Also, this paper propose the result of investigation of influence of inherent attribute to customer satisfaction, and the possibility of application of estimated prediction model for improvement of the total customer satisfaction of system product based on the inherent attributes of the product.

\section{Concepts}

\subsection{Concept of Prediction Model}

Figure 1 shows the concept of system product implementation supported by ISO/IEC25000 (SQuaRE) series.

Customers have needs for the inherent attributes of system product. In order to perform development, at first, developers should specify a quality requirement from the

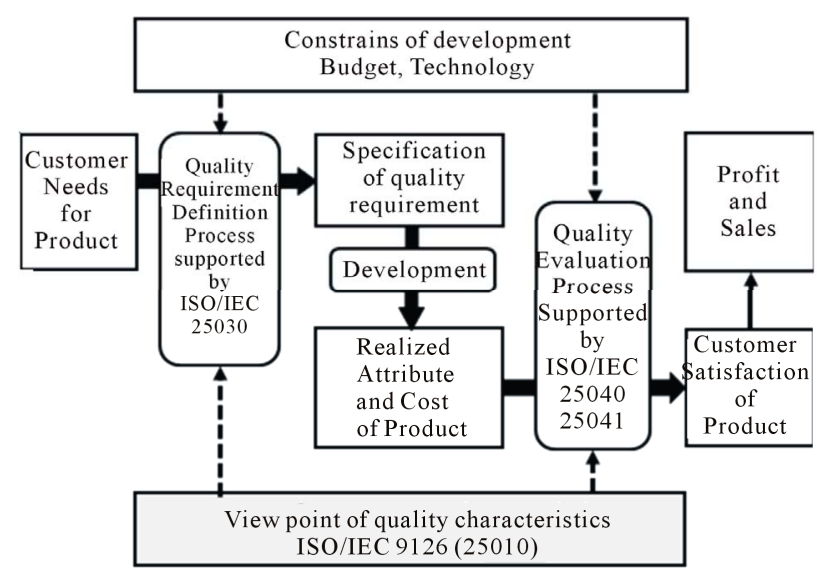

Figure 1. Concept of prediction model of customer satisfaction for system product quality. 
view point of customer's needs. We should make specifications that at first we confirm the real needs of the customers at the beginning, and described the concrete inherent attribute that you should realize with a product.

After development, developer and customer should evaluate the target system product based on the quality requirement specification in order to assure the quality of developed product.

From Figure 1, ISO/IEC25030 provides the requirements and recommendations for specifying the quality requirements from the view point of selected customer's needs. The specified quality requirements should be used as the criteria of system and software product evaluation. Quality requirements for system can be specified using the process defined in ISO/IEC25030 [2] based on the quality model include six quality characteristics described in ISO/IEC9126-1. From Figure 1, system quality evaluation can be performed by using ISO/IEC25040 [3] and 25041 [4] based on the specified quality requirements, which are specified by using ISO/IEC25030 during system design phase.

Table 1 is the example of inherent attributes of the sample products which used in this study. A good product is the product which is high quality in a sufficiency degree of the product for the customer needs, and it is thought that the satisfaction of quality of the product for the customer is high. Customer satisfaction or negative opinion of inherent attribute of the product may be as a target of decision for the purchase. It is thought that the customer satisfaction of the product depends on the inherent attribute of a product, which comes out from the customer needs for the target product. The developer should implement the inherent attribute of the product to the target system based on the customer needs.

After completion of products development, concrete inherent attribute of product and production cost is decided. If the customer satisfaction for an inherent attribute and the price of product is high, as a result, the sales of the product increase, and it is thought that profitability may increase.

In this study, at first, I calculate the observed total customer satisfaction for the product from the viewpoint of six quality characteristics of the ISO/IEC9126 based on the method that I showed for the beginning in a precedent study. After that, I investigate the relations between the inherent attribute of product and the observed total customer satisfaction according to six quality characteristics for the product.

Furthermore, I assume the observed total customer satisfaction according to six quality characteristics as an objective variable and assume the inherent attributes of product as an explanation variable, and performed a multiple regression analysis. Also, this study inspects the effectiveness of the prediction model that can estimate total customer satisfaction judging from the viewpoint of six quality characteristics of the product from the inherent attributes of the products.

\subsection{Concept of System and Software Quality Model}

Figure 2 shows the structure of the Software Quality Model defined in ISO/IEC9126-1. Recently, ISO/ IEC9126-1 have replaced by ISO/IEC25010:2011, but ISO/ IEC9126-1 is widely recognized and actually used, then this study focus on the ISO/IEC9126-1.

From Figure 2, this model includes the six quality characteristics for system and software such as Functionality, Reliability, Usability, Efficiency, Portability and Maintainability.

Functionality can provide the ultimate function for supporting the improvement of work. And, Usability provides the ease of use of the system.

Reliability and Efficiency represents the capability possessed in the system, and is the characteristic associated with sustaining the quality objectives determined by the Functionality and Usability.

Maintainability and Portability provide the capability of the system to adapt to changes in the system environment and the usage environment.

\section{Summaries}

This study first collects the customers complaints, i.e., expression of customer dissatisfaction posted on a review of website where customers who actually purchased personal computer related products post their complaints as shown in Table 2. The study, then, classifies the posted customer complaints based on the six quality characteristics defined in the ISO/IEC9126-1, obtains from questionnaires a weight for each quality characteristic to represent how important the quality characteristic is to the customer, applies the weights to the six quality characteristics, and quantifies the degree of customer satisfaction for each quality characteristic as shown in Table 3.

The degree of total customer satisfaction is obtained from the each customer satisfactions of six quality characteristics for the each target system.

This study has calculated the observed total customer satisfaction by using customer satisfaction of each six quality characteristics based on the result of precedent study [11].

Second, this study have collected inherent attributes of target products, i.e., CPU, HDD capacity, Wait of body, Drive time, as shown in Table 1. The study has performed correlation analysis of the degree of inherent attributes of LPCs and has confirmed the independency of each inherent attributes or not. In addition, the study has performed multiple-regression analyses and for performing the multiple regression analysis, has assigned the 


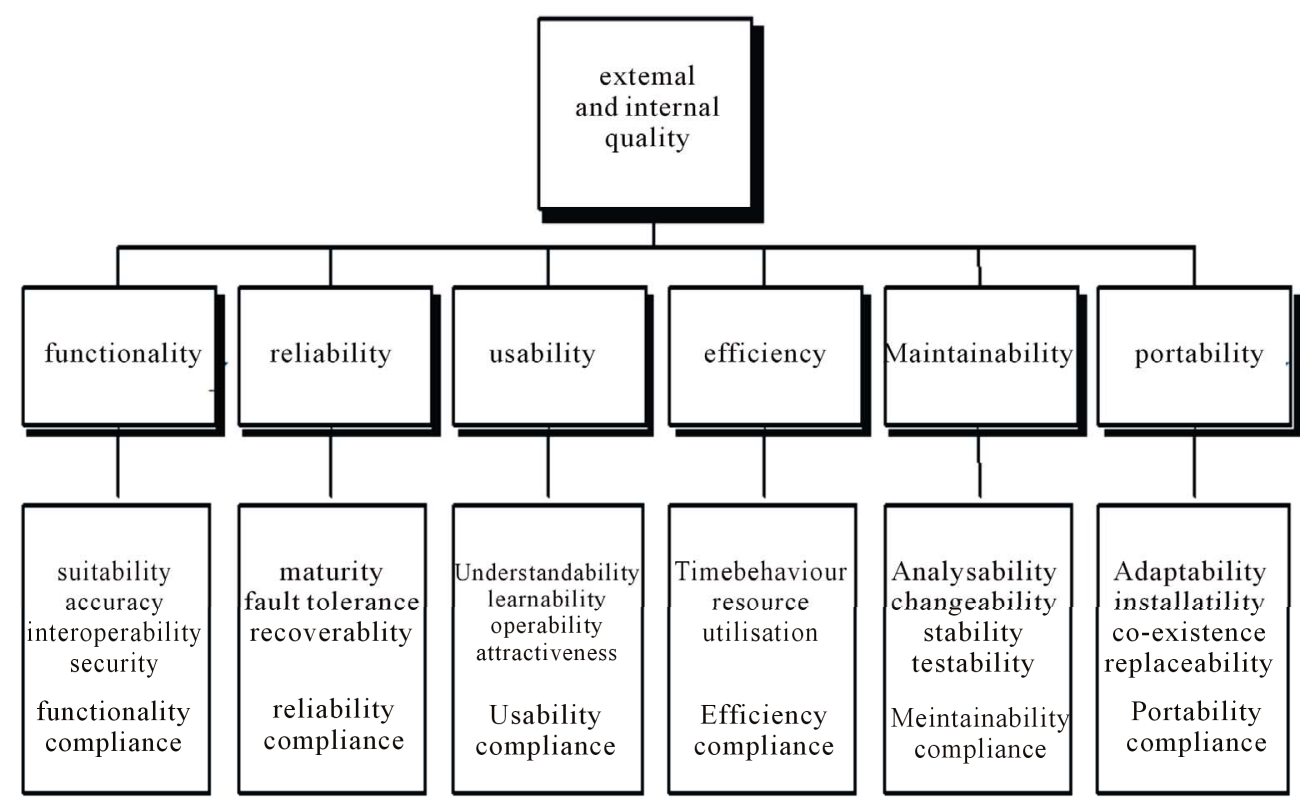

Figure 2. System and software product quality model -ISO/IEC9126-1:2001 [6].

Table 1. Example of the inherent attribute of LPCs.

\begin{tabular}{|c|c|c|c|c|c|c|c|c|c|c|c|c|c|c|}
\hline & \multicolumn{14}{|c|}{ Inherent Attributes } \\
\hline & $\stackrel{\vartheta}{0}$ & 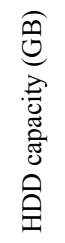 & ڤ & 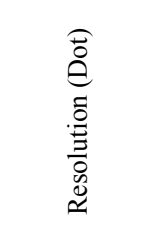 & 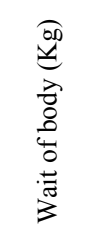 & 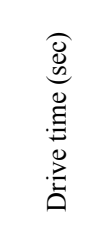 & 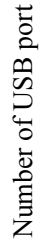 & 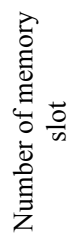 & 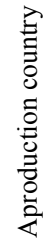 & 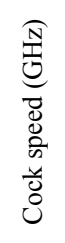 & 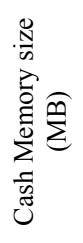 & 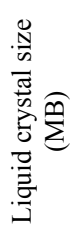 & 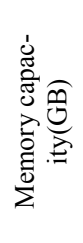 & 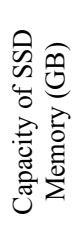 \\
\hline & $\mathrm{a}_{i}$ & $\mathrm{~b}_{i}$ & $\mathrm{c}_{i}$ & $\mathrm{~d}_{i}$ & $\mathrm{e}_{i}$ & $\mathrm{f}_{i}$ & $\mathrm{~g}_{i}$ & $\mathrm{~h}_{i}$ & $\mathrm{i}_{i}$ & $\mathrm{j}_{i}$ & $\mathrm{k}_{i}$ & $\mathrm{~m}_{i}$ & $\mathrm{n}_{i}$ & $\mathrm{o}_{i}$ \\
\hline $\mathrm{S}_{1}$ & Core i5 2410M & 0 & $\begin{array}{c}\text { Intel HD } \\
\text { Graphics } 3000\end{array}$ & $1366 \times 768$ & 1.0000 & 13.0000 & 3 & 1 & $\mathrm{~J}$ & 2.3 & 3 & 10.1 & 2 & 128 \\
\hline $\mathrm{S}_{2}$ & Core i5 460M & 0 & $\begin{array}{l}\text { Intel HD } \\
\text { Graphics }\end{array}$ & $1366 \times 768$ & 1.2050 & 12.0000 & 3 & 1 & $\mathrm{~J}$ & 2.53 & 3 & 10.1 & 2 & 128 \\
\hline $\mathrm{S}_{3}$ & Core i3 2310M & 500 & $\begin{array}{c}\text { RADEON HD } \\
6470 \mathrm{M}\end{array}$ & $1366 \times 768$ & 1.7200 & 8.5000 & 3 & 1 & $\mathrm{~J} / \mathrm{C}$ & 2.1 & 3 & 13.3 & 4 & 0 \\
\hline $\mathrm{S}_{4}$ & Core i3 380M & 160 & $\begin{array}{l}\text { Intel HD } \\
\text { Graphics }\end{array}$ & $1366 \times 768$ & 1.1850 & 7.5000 & 3 & 1 & $\mathrm{~J}$ & 2.53 & 3 & 10.1 & 2 & 0 \\
\hline $\mathrm{S}_{5}$ & $\begin{array}{l}\text { Pentium Dul-Core } \\
\text { B940 }\end{array}$ & 640 & $\begin{array}{l}\text { Intel HD } \\
\text { Graphics }\end{array}$ & $1366 \times 768$ & 2.4000 & 2.1000 & 3 & 2 & $\mathrm{~T} / \mathrm{C}$ & 2 & 2 & 15.6 & 4 & 0 \\
\hline $\mathrm{S}_{6}$ & Core i 5 2410M & 750 & $\begin{array}{c}\text { Intel HD } \\
\text { Graphics } 3000\end{array}$ & $1366 \times 768$ & 2.4000 & 2.3000 & 2 & 2 & $\mathrm{~T} / \mathrm{C}$ & 2.3 & 3 & 15.6 & 4 & 0 \\
\hline $\mathrm{S}_{7}$ & Core i5 2520M & 500 & $\begin{array}{c}\text { Intel HD } \\
\text { Graphics } 3000\end{array}$ & $1280 \times 800$ & 1.3300 & 15.5000 & 3 & 1 & $\mathrm{~J}$ & 2.5 & 3 & 12.1 & 4 & 0 \\
\hline $\mathrm{S}_{8}$ & Core i5 2520M & 640 & $\begin{array}{c}\text { Intel HD } \\
\text { Graphics } 3000\end{array}$ & $1280 \times 800$ & 1.3400 & 16.5000 & 3 & 1 & $\mathrm{~J}$ & 2.5 & 3 & 12.1 & 4 & 0 \\
\hline $\mathrm{S}_{10}$ & Core i7 2630QM & 640 & $\begin{array}{l}\text { GeForce } \\
\text { GT 540M }\end{array}$ & $1920 \times 1080$ & 3.2000 & 2.5000 & 3 & 3 & $\mathrm{~J} / \mathrm{C}$ & 2 & 6 & 16 & 8 & 0 \\
\hline
\end{tabular}

$\mathrm{S}_{i}$ : Example of target laptop personal computers $(i$ : Number of sample product $(i=1-35))$. 
Table 2. Example of negative review from web-site.

\begin{tabular}{|c|c|c|c|c|c|c|c|c|c|c|c|c|c|}
\hline \multirow{2}{*}{$\begin{array}{l}\text { View point of Six } \\
\text { quality characteristics }\end{array}$} & \multirow{2}{*}{\multicolumn{2}{|c|}{ Category of negative review }} & \multicolumn{11}{|c|}{ Number of complaints (count) } \\
\hline & & & $\mathrm{S}_{1}$ & $\mathrm{~S}_{2}$ & $\mathrm{~S}_{3}$ & $\mathrm{~S}_{4}$ & $\mathrm{~S}_{5}$ & $\mathrm{~S}_{6}$ & $\mathrm{~S}_{7}$ & $\mathrm{~S}_{8}$ & $\mathrm{~S}_{9}$ & $\mathrm{~S}_{10}$ & $\mathrm{~S}_{i}$ \\
\hline \multirow{2}{*}{ functionality } & Number of Built-in application software & $\mathrm{a} 1_{i}$ & 0 & 0 & 1 & 0 & 0 & 0 & 0 & 0 & 0 & 0 & 0 \\
\hline & A Kind of OS & $\mathrm{a} 2_{i}$ & 0 & 0 & 1 & 0 & 0 & 0 & 0 & 1 & 0 & 0 & 0 \\
\hline \multirow{3}{*}{ usability } & Easiness in seeing screen & $\mathrm{b} 1_{i}$ & 14 & 3 & 11 & 3 & 3 & 11 & 2 & 0 & 2 & 6 & 3 \\
\hline & Easiness to use Keyboard & $\mathrm{b} 2_{i}$ & 6 & 3 & 5 & 6 & 2 & 12 & 3 & 5 & 1 & 12 & 4 \\
\hline & Wait of body & $\mathrm{b} 3_{i}$ & 5 & 0 & 8 & 0 & 2 & 1 & 0 & 1 & 2 & 1 & 0 \\
\hline \multirow{3}{*}{ readability } & Number of fault & $\mathrm{c} 1_{i}$ & 1 & 0 & 1 & 1 & 0 & 4 & 0 & 0 & 0 & 0 & 0 \\
\hline & A production country & $\mathrm{c} 2_{i}$ & 3 & 0 & 4 & 5 & 0 & 7 & 0 & 0 & 1 & 2 & 1 \\
\hline & Capacity of Battery & $\mathrm{c} 3_{i}$ & 6 & 1 & 1 & 12 & 0 & 0 & 0 & 0 & 7 & 9 & 1 \\
\hline \multirow{2}{*}{ efficiency } & Transaction speed & $\mathrm{d} 1_{i}$ & 2 & 0 & 3 & 3 & 0 & 1 & 1 & 4 & 0 & 0 & 1 \\
\hline & Drive time & $\mathrm{d} 2_{i}$ & 13 & 0 & 0 & 8 & 0 & 3 & 0 & 2 & 1 & 1 & 0 \\
\hline portability & Number of USB port & $\mathrm{e} 1_{i}$ & 7 & 1 & 2 & 0 & 1 & 0 & 1 & 0 & 0 & 3 & 3 \\
\hline maintainability & Customer support & $\mathrm{fl}_{i}$ & 1 & 1 & 0 & 0 & 0 & 0 & 1 & 0 & 1 & 1 & 0 \\
\hline \multicolumn{2}{|c|}{ Total number of Review } & $\mathrm{RC}_{i}$ & 58 & 22 & 38 & 41 & 26 & 78 & 23 & 19 & 21 & 35 & 32 \\
\hline
\end{tabular}

$\mathrm{S}_{i}$ : Example of target laptop personal computers ( $i$ : Number of sample product $(i=1-35)$ ).

Table 3. Importance of customerneeds by six quality characteristics.

\begin{tabular}{|c|c|c|c|c|c|c|c|c|c|c|}
\hline \multirow{2}{*}{$\begin{array}{c}\text { View point of Six } \\
\text { quality characteristics }\end{array}$} & \multirow{2}{*}{\multicolumn{2}{|c|}{ Category of Questions }} & \multicolumn{6}{|c|}{ Samples of Customers } & \multirow{2}{*}{\multicolumn{2}{|c|}{ Weight: Importance Ratio }} \\
\hline & & & \multirow{2}{*}{$\begin{array}{l}\mathrm{U}_{1} \\
15\end{array}$} & \multirow{2}{*}{$\begin{array}{l}\mathrm{U}_{2} \\
10\end{array}$} & \multirow{2}{*}{$\begin{array}{l}\mathrm{U}_{3} \\
10\end{array}$} & \multirow{2}{*}{$\begin{array}{l}\mathrm{U}_{4} \\
10\end{array}$} & \multirow{2}{*}{$\begin{array}{c}\mathrm{U}_{5} \\
8\end{array}$} & \multirow{2}{*}{$\begin{array}{l}\mathrm{U}_{n} \\
15\end{array}$} & & \\
\hline \multirow{2}{*}{ functionality } & Number of Built-in application software & $\mathrm{Sa}_{n}$ & & & & & & & \multirow{2}{*}{ M } & \multirow{2}{*}{0.6350} \\
\hline & A Kind of OS & $\mathrm{Sa} 2_{n}$ & 9 & 4 & 3 & 9 & 13 & 12 & & \\
\hline \multirow{4}{*}{ usability } & Easiness in seeing screen & $\mathrm{Sb} 1_{n}$ & 4 & 2 & 6 & 3 & 5 & 6 & \multirow{4}{*}{$\mathrm{N}$} & \multirow{4}{*}{0.7260} \\
\hline & Screen Size & $\mathrm{Sb} 2_{n}$ & 5 & 3 & 14 & 8 & 6 & 5 & & \\
\hline & Easiness to use Keyboard & $\mathrm{Sb} 3_{n}$ & 6 & 9 & 15 & 12 & 4 & 7 & & \\
\hline & Wait of body & $\mathrm{Sb} 4_{n}$ & 8 & 6 & 9 & 7 & 11 & 11 & & \\
\hline \multirow{3}{*}{ readability } & Number of fault & $\mathrm{Sc}_{n}$ & 3 & 5 & 4 & 1 & 12 & 8 & \multirow{3}{*}{$\mathrm{O}$} & \multirow{3}{*}{0.7610} \\
\hline & A production country & $\mathrm{Sc} 2_{n}$ & 12 & 12 & 12 & 5 & 15 & 10 & & \\
\hline & Capacity of Battery & $\mathrm{Sc} 3_{n}$ & 2 & 8 & 7 & 4 & 9 & 2 & & \\
\hline \multirow{2}{*}{ efficiency } & Transaction speed & $\mathrm{Sd} 1_{n}$ & 7 & 7 & 8 & 3 & 10 & 4 & \multirow{2}{*}{$\mathrm{P}$} & \multirow{2}{*}{1.0000} \\
\hline & Drive time & $\mathrm{Sd} 2_{n}$ & 1 & 1 & 1 & 2 & 3 & 3 & & \\
\hline \multirow{2}{*}{ portability } & Number of USB port & $\mathrm{Se}_{n}$ & 13 & 11 & 13 & 11 & 7 & 14 & \multirow[b]{2}{*}{ Q } & \multirow{2}{*}{0.4440} \\
\hline & Number of Memory Slot & $\mathrm{Se} 2_{n}$ & 10 & 14 & 11 & 13 & 2 & 13 & & \\
\hline maintainability & Customer support & $\mathrm{Sfl}_{n}$ & 14 & 13 & 5 & 14 & 14 & 9 & $\mathrm{R}$ & 0.5480 \\
\hline
\end{tabular}

$\mathrm{U}_{n}$ : Example of customers $(n:$ Number of customers $(n=1-\mathrm{TN}), \mathrm{TN}=61)$.

degree of total customer satisfaction as an objective variable and assigned the degrees of inherent attributes as explanatory variables. Furthermore, the study has developed the model that actually predicts the degree of total customer satisfaction of the target products from the degree inherent attributes of product. The possibility of whether or not the degree of observed total customer satisfaction corresponding to the specified products could be derived from the degree of inherent attributes corresponding to the target product during the system design phase was verified.

Finally, the study discusses the validity of estimated prediction models based on the significance of the developed prediction model and possibility of application of proposed prediction model and approaches.

In recent years, due to the explosion of the Internet, purchasing behaviours of customers have significantly changed. For example, an increasing number of custom- ers can order a product directly from an electric commerce site without visiting brick-and-motor shops while remaining at home. The degree of customer satisfaction is aindicators used in marketing that represents how a product or service produced by a company meets customer expectation.

This study focuses on online reviews posted on the Internet, an effective alternative to face-to-face interviews of customers, and uses the online negative reviews of a system product as the data of investigation. This study collects and uses online reviews of products posted at a web-site, kakaku.com [12] as customer's expression of his/her dissatisfaction of system products. Table 1 shows the part of collection data concerning negative review from web-site, which total number of type of LPCs is 35 and total number of review is 457.

From Table 2, this study counts the number of online negative reviews for each concrete category of interest of 
LPCs from the view point of the six quality characteristics. This study collects and classifies online negative reviews from the view point of the six quality characteristics in this manner. Furthermore, for each product, this study obtains the degree of importance for each of the six quality characteristics taking into account the interest of attribute of LPCs (i.e., weight for) by the six quality characteristics as shown in Table 3.

Table 3 shows the example of questionnaires and the obtained result of importance of quality needs by each six quality characteristics obtain from questionnaires.

For example, the questionnaires have asked to the customers, "in purchasing a LPC, what attributes are important?" and the customers have assigned the numeric order number between 1 and 15 based on the importance.

The meaning of order number 1 is the most important attribute for the quality characteristic, and the weights for the six quality characteristics have normalized in the range from 0 to 1 .

This study quantitatively calculatesthe importance of customer needs for each quality characteristics.

For example, theimportance of functionality as $\mathrm{M}$ is obtained from the following Equations (1) and (2).

$$
\begin{gathered}
M^{\prime}=\frac{\sum_{n=1}^{T N}\left(O N+1-S a 1_{n}\right)+\sum_{n=1}^{T N}\left(O N+1-S a 2_{n}\right)}{T N \times 2} \\
M=\frac{M^{\prime}}{\max \left(M^{\prime}, N^{\prime}, O^{\prime}, P^{\prime}, Q^{\prime}, R^{\prime}\right)}
\end{gathered}
$$

$M$ : Importance ratio of Functionality (weight);

$M$ ': Importance ratio of Functionality (Un-Normalised);

$S a 1_{n}$ : Order number of importance $\left(S a 1_{n}=1 \sim O N\right)$;

$\mathrm{Sa}_{n}$ : Order number of importance $\left(\mathrm{Sa}_{n}=1 \sim \mathrm{ON}\right)$;

$n$ : Number of customers $(n=1 \sim T N)$;

$O N$ : Maximum order number $(O N=15)$;

$T N$ : Total number of customers $(T N=61)$.

From Table 2, TN is the total number of customers, which total number of customersis 61 , and pis the weight for the efficiency determined from the questionnaires. This study focused on laptop computers (LPCs).

Reasons for choosing LPCs are, at first, LPCs have at-tribute and characteristics that correspond to the six quality characteristics, and there is a large amount of data available on the non-functionality and non-quantitatively requirements on online review web-sites. Table 1 shows the part of collection data concerning inherent attributes of LPCs from web-site, which total number of type of LPCs is 35 . Inherent attribute refers to the degree to which attributes of target product have the intrinsic potential to satisfy stated and implied needs when LPCs is used under specified conditions. From the inherent point of view, Attribute of LPCs is product itself, in par ticularto shown in Table 1.
Above consideration, price is not inherent attribute but assigned attribute. If we wish to evaluate the customer satisfaction from the view point of product quality, we should use only inherent attribute of target product itself.

Then, this study use only inherent attributes of target product without price.

\section{Degreeof Customer Satisfaction}

Table 3 shows the parts of result about degree of the observed customer satisfaction for each quality characteristics. By applying the weight for each of the six quality characteristics, this study has quantitatively calculated the degree of customer satisfaction for each six quality characteristics. For example, the degree of customer satisfaction for efficiency as $\mathrm{SD}_{i}$ is obtained as following Equations (3) and (4)

$$
\begin{gathered}
d d 1_{i}=\frac{d 1_{i} \times p}{R C_{i}} \\
S D_{i}=1-\sqrt{d d 1_{i}^{2}+d d 2_{i}^{2}}
\end{gathered}
$$

$S D_{i}$ : Customer satisfaction of efficiency;

$d d 1_{i}$ : Ratio of un-satisfaction of efficiency by each category;

$d 1_{i}$ : Number of negative review of efficiency;

$i$ : Number of sample product $(i=1-35)$;

$P$ : Importance ratio of efficiency (weight);

$R C_{i}$ : Total number of online reviews of a given product.

This study has quantitatively calculated the degree of observed total customer satisfaction from the view point of six quality characteristic included in the ISO/IEC9126 quality model.

The degree of observed total customer satisfaction is obtained based on the consideration of independency among six quality characteristics as following Equation (5) as shown in Table 4.

$$
T S_{i}=\sqrt{S A_{i}^{2}+S B_{i}^{2}+S C_{i}^{2}+S D_{i}^{2}+S E_{i}^{2}+S F_{i}^{2}}
$$

$T S_{i}$ : Observed total customer satisfaction.

This study has predicted the degree of total customer satisfaction. The degree of predicted total customer satisfactions is obtained by using inherent attributes of LPCs as following Equation (6).

$$
P S_{i}=r_{0}+r_{1} \times a_{i}+r_{2} \times b_{i}+\cdots+r_{n} \times o_{i}
$$

$P S_{i}$ : Predicting total customer satisfaction;

$r_{n}$ : partial regression coefficient $(n=1-14)$.

\section{Verification}

\subsection{Correlation Matrix between Observed Total Customer Satisfaction and Attributes}

Table 5 shows the result of correlation analysis among 
Table 4. Degree of observed customer satisfaction.

\begin{tabular}{cccccccc}
\hline \multirow{2}{*}{\begin{tabular}{c} 
Number of $\begin{array}{c}\text { Sample } \\
\text { products }\end{array}$ \\
\cline { 2 - 8 }
\end{tabular}} & Functionality & Usability & Reliability & Efficiency & Portability & Maintainability & Total \\
\cline { 2 - 8 } & SA & SB & SC & SD & SE & SF & TS \\
\hline $\mathrm{S}_{1}$ & 1.0000 & 0.7993 & 0.9110 & 0.7732 & 0.9464 & 0.9906 & 2.2234 \\
$\mathrm{~S}_{2}$ & 1.0000 & 0.8600 & 0.9654 & 1.0000 & 0.9798 & 0.9751 & 2.3627 \\
$\mathrm{~S}_{3}$ & 0.9764 & 0.7231 & 0.9150 & 0.9211 & 0.9766 & 1.0000 & 2.2618 \\
$\mathrm{~S}_{4}$ & 1.0000 & 0.8812 & 0.7580 & 0.7916 & 1.0000 & 1.0000 & 2.2311 \\
$\mathrm{~S}_{5}$ & 1.0000 & 0.8849 & 1.0000 & 1.0000 & 0.9829 & 1.0000 & 2.3977 \\
$\mathrm{~S}_{6}$ & 1.0000 & 0.8482 & 0.9213 & 0.9595 & 1.0000 & 1.0000 & 2.3428 \\
$\mathrm{~S}_{7}$ & 1.0000 & 0.8862 & 1.0000 & 0.9565 & 0.9807 & 0.9762 & 2.3696 \\
$\mathrm{~S}_{8}$ & 0.9666 & 0.8052 & 1.0000 & 0.7646 & 1.0000 & 1.0000 & 2.2732 \\
$\mathrm{~S}_{9}$ & 1.0000 & 0.8963 & 0.7438 & 0.9524 & 1.0000 & 0.9739 & 2.2830 \\
$\mathrm{~S}_{10}$ & 1.0000 & 0.7209 & 0.7995 & 0.9714 & 0.9619 & 0.9843 & 2.2354 \\
$\mathrm{~S}_{i}$ & 1.0000 & 0.8866 & 0.9664 & 0.9688 & 0.9584 & 1.0000 & 2.3615 \\
\hline
\end{tabular}

$\mathrm{S}_{i}$ : Example of target laptop personal computers (i: Number of sample product $(i=1-35)$ ).

Table 5. Correlation matrix between TS and inherent attributes of LPCs.

\begin{tabular}{|c|c|c|c|c|c|c|c|c|c|c|c|c|c|c|c|}
\hline & 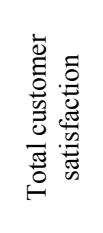 & 己 & 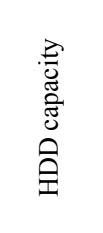 & 灾 & 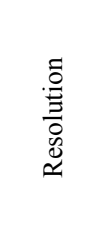 & 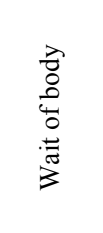 & 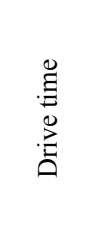 & 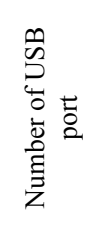 & 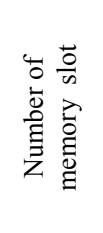 & 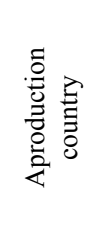 & 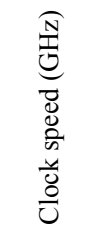 & 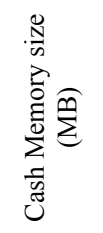 & 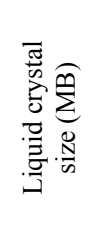 & 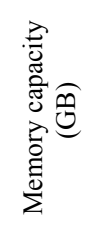 & 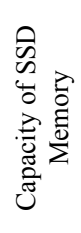 \\
\hline & $T S$ & $\mathrm{a}$ & $\mathrm{b}$ & $\mathrm{c}$ & d & e & $\mathrm{f}$ & $\mathrm{g}$ & $\mathrm{h}$ & $\mathrm{i}$ & $\mathrm{j}$ & K & $\mathrm{m}$ & $\mathrm{n}$ & o \\
\hline & & $\mathrm{r}_{1}$ & $r_{2}$ & $r_{3}$ & $r_{4}$ & $r_{5}$ & $r_{6}$ & $r_{7}$ & $r_{8}$ & $\mathrm{r}_{9}$ & $\mathrm{r}_{10}$ & $\mathrm{r}_{11}$ & $r_{12}$ & $\mathrm{r}_{13}$ & $\mathrm{r}_{14}$ \\
\hline TS & 1.000 & & & & & & & & & & & & & & \\
\hline $\mathrm{a}$ & 0.292 & 1.000 & & & & & & & & & & & & & \\
\hline $\mathrm{b}$ & -0.122 & 0.316 & 1.000 & & & & & & & & & & & & \\
\hline $\mathrm{c}$ & -0.056 & 0.347 & 0.304 & 1.000 & & & & & & & & & & & \\
\hline $\mathrm{d}$ & -0.125 & 0.137 & 0.217 & 0.346 & 1.000 & & & & & & & & & & \\
\hline $\mathrm{e}$ & -0.140 & 0.262 & 0.679 & 0.229 & 0.442 & 1.000 & & & & & & & & & \\
\hline $\mathrm{f}$ & 0.234 & 0.088 & -0.468 & -0.042 & -0.210 & -0.744 & 1.000 & & & & & & & & \\
\hline $\mathrm{g}$ & 0.077 & 0.110 & 0.326 & -0.118 & 0.180 & 0.501 & -0.264 & 1.000 & & & & & & & \\
\hline $\mathrm{h}$ & -0.435 & 0.040 & 0.513 & 0.246 & 0.352 & 0.691 & -0.721 & 0.146 & 1.000 & & & & & & \\
\hline $\mathrm{i}$ & 0.148 & 0.115 & -0.189 & -0.166 & 0.196 & -0.357 & 0.460 & 0.227 & -0.485 & 1.000 & & & & & \\
\hline $\mathrm{j}$ & 0.193 & 0.394 & -0.092 & -0.359 & -0.252 & -0.036 & 0.181 & -0.025 & -0.337 & 0.212 & 1.000 & & & & \\
\hline $\mathrm{k}$ & 0.042 & 0.589 & 0.446 & 0.527 & 0.513 & 0.541 & -0.213 & 0.202 & 0.209 & -0.014 & -0.064 & 1.000 & & & \\
\hline $\mathrm{m}$ & -0.128 & 0.270 & 0.727 & 0.211 & 0.340 & 0.947 & -0.724 & 0.349 & 0.677 & -0.422 & 0.007 & 0.454 & 1.000 & & \\
\hline $\mathrm{n}$ & 0.166 & 0.577 & 0.646 & 0.422 & 0.496 & 0.560 & -0.246 & 0.332 & 0.370 & -0.058 & -0.156 & 0.672 & 0.493 & 1.000 & \\
\hline o & 0.199 & 0.085 & -0.623 & -0.108 & -0.082 & -0.416 & 0.413 & -0.119 & -0.483 & 0.325 & 0.170 & -0.007 & -0.503 & -0.266 & 1.000 \\
\hline
\end{tabular}

$\mathrm{r}_{n}$ : partial regression coefficient $(n=1-14)$. TS: Observed total customer satisfaction.

inherent attributes and $T S_{i}$ (Obtained total customer satisfaction from Equation (5)) of LPCs.

Since the correlation coefficient, a, f, h, j, o are high, there is a correlation among obtained total customer satisfaction from the view point of concerning inherent at tributes and dependency of each are recognized. 
Also, correlation between 1) CPU and 2) Clock speed is recognized.

\subsection{Multiple Regressions Analysis among Observed Total Customer Satisfaction and Attributes}

Table 6 shows the three types of developed prediction models based on the consideration about the result of correlation analysis. From Table 6, multiple-regression analysis between observed customer satisfaction and concerning inherent attributes of the each types of prediction model shows that the value of multiple-regression coefficients and the determination coefficients are 0.5610 and 0.3147 , respectively as prediction model type 2 . In addition, maximum value of F-test is 3.443 . Since it is higher than $5 \%$ significance level $\mathrm{F}_{0}=2.689$, this study confirmed that there is significance in predicting the degree of total customer satisfaction.

The cause and effect relationship between the degree of observed total customer satisfaction and those corresponding inherent attributes of LPCs could observe.

Based on the consideration of above result, this study confirmed that causal relationship among the observed total customer satisfaction and concerning inherent attributes of sample products.

This study verified the validity of the introduced prediction models of quantitatively predicting total customer satisfaction using the inherent attributes of target LPCs.

Table 7 shows the parts of the result of degree of predicted total customer satisfaction, which predicted by each types of prediction models.

\section{Concluding Remarks}

Based on the results of this study, realized entire customer satisfaction of system product can be predicted and compared by using implemented inherent attributes of target system products during design stage of development. Proposed prediction models and application may be very useful for estimate the total customer satisfaction of developing product, and compare with the configuretion of alternative candidate products, and provide the solutions for taking the higher customer satisfaction of the product. Also, proposed prediction models may be used as the following:

To predict influence on customer satisfaction of the inherent attribute of system products to implement at a

Table 6. Result of multiple regression analysis.

\begin{tabular}{|c|c|c|c|c|c|c|c|}
\hline \multirow{2}{*}{\multicolumn{3}{|c|}{$\begin{array}{c}\text { Prediction Models for PS } \\
\text { PS: Predicting total customer Satisfaction }\end{array}$}} & \multicolumn{5}{|c|}{ Result } \\
\hline & & & \multirow{2}{*}{$\begin{array}{l}\text { R: Multiple } \\
\text { correlation } \\
\text { coefficient }\end{array}$} & \multirow{2}{*}{$\begin{array}{c}\mathrm{R}^{2} \text { : coefficient of } \\
\text { determination }\end{array}$} & \multirow{2}{*}{ F Value } & \multicolumn{2}{|c|}{$\mathrm{F}_{0}(\mathrm{~m}, 35,0.05)$} \\
\hline & & & & & & $\mathrm{m}$ & $\mathrm{F}_{0}$ \\
\hline \multirow{3}{*}{$\begin{array}{l}\text { Consider only } \\
\text { inherent attributes }\end{array}$} & Type 1 & $=\mathrm{r}_{0}+\mathrm{r}_{1} \times \mathrm{a}+\mathrm{r}_{6} \times \mathrm{f}+\mathrm{r}_{8} \times \mathrm{h}+\mathrm{r}_{10} \times \mathrm{j}+\mathrm{r}_{15} \times \mathrm{o}$ & 0.5757 & 0.3314 & 2.8753 & 5 & 2.5336 \\
\hline & Type 2 & $=\mathrm{r}_{0}+\mathrm{r}_{1} \times \mathrm{a}+\mathrm{r}_{6} \times \mathrm{f}+\mathrm{r}_{8} \times \mathrm{h}+\mathrm{r}_{15} \times \mathrm{o}$ & 0.5610 & 0.3147 & 3.4436 & 4 & 2.6896 \\
\hline & Type 3 & $=\mathrm{r}_{0}+\mathrm{r}_{6} \times \mathrm{f}+\mathrm{r}_{8} \times \mathrm{h}+\mathrm{r}_{10} \times \mathrm{j}+\mathrm{r}_{15} \times \mathrm{o}$ & 0.4513 & 0.2036 & 1.9177 & 4 & 2.6896 \\
\hline
\end{tabular}

Table 7. Predictingvalue of total customer satisfaction.

\begin{tabular}{|c|c|c|c|c|}
\hline \multirow{3}{*}{ Sample products } & \multicolumn{3}{|c|}{ Result of prediction } & \multirow{2}{*}{ Observed customer satisfaction } \\
\hline & Type 1 & Type 2 & Type 3 & \\
\hline & $P S_{i}$ & $P S_{i}$ & $P S_{i}$ & $T S_{i}$ \\
\hline $\mathrm{S}_{1}$ & 2.2871 & 2.3033 & 2.3040 & 2.2234 \\
\hline $\mathrm{S}_{2}$ & 2.3005 & 2.3043 & 2.2980 & 2.3627 \\
\hline $\mathrm{S}_{3}$ & 2.2783 & 2.2850 & 2.2853 & 2.2618 \\
\hline $\mathrm{S}_{4}$ & 2.2754 & 2.2643 & 2.2958 & 2.2311 \\
\hline $\mathrm{S}_{5}$ & 2.2706 & 2.2738 & 2.2946 & 2.3977 \\
\hline $\mathrm{S}_{6}$ & 2.2921 & 2.2970 & 2.2932 & 2.3428 \\
\hline $\mathrm{S}_{7}$ & 2.3123 & 2.3146 & 2.3048 & 2.3696 \\
\hline $\mathrm{S}_{8}$ & 2.2929 & 2.3010 & 2.3023 & 2.2732 \\
\hline $\mathrm{S}_{9}$ & 2.2955 & 2.3106 & 2.3088 & 2.2830 \\
\hline $\mathrm{S}_{10}$ & 2.3113 & 2.3138 & 2.3042 & 2.2354 \\
\hline $\mathrm{S}_{i}$ & 2.3455 & 2.3336 & 2.2951 & 2.3615 \\
\hline
\end{tabular}

$\mathrm{S}_{i}$ : Example of target laptop personal computers $(i$ : Number of sample product $(i=1-35))$. 
design stage and may be able to simulate it;

Could realize the most suitable combination of parts in to the target system;

The most suitable design of the product can be performed and may be able to realize the cost effective high quality product;

With the same cost, a product having higher customer satisfaction may come out;

The possibility of the application to other systems.

In the future study, the author plans to study the influence of price and application of proposed models to each six quality characteristics.

\section{Acknowledgements}

The authors are grateful to members of production system research office at Graduate School of Factory of Sciece and Engineering HOSEI University who their contributions and support to make the discussion.

\section{REFERENCES}

[1] ISO/IEC25000, "Software Engineering-Software Product Quality Requirements and Evaluation (SQuaRE) — Guide to SQuaRE," Int'l Organization for Standardization, 2005.

[2] ISO/IEC25030, "Software Engineering-Software Product Quality Requirements and Evaluation (SQuaRE)-Quality Requirement," Int'l Organization for Standardization, 2007.
[3] ISO/IEC25040, "Software Engineering-System and Software Quality Requirements and Evaluation (SQuaRE) Evaluation Process," 2011.

[4] ISO/IEC25041, "Software Engineering-System and Software Quality Requirements and Evaluation (SQuaRE)Evaluation Guide for Developers, Acquirers and Independent Evaluators, 2012.

[5] ISO/IEC25010, "Software Engineering-System and Software Quality Requirements and Evaluation (SQuaRE) - System and Software Quality Model," Int'l Organization for Standardization, 2011.

[6] ISO/IEC9126-1, "Software Engineering-Product Quality -Part 1: Quality Model," 2001.

[7] K, Esaki, "System Quality Requirement and Evaluation, Importance of Application of the ISO/IEC25000 Series," Global Perspective on Engineering Management, Vol. 2, No. 2, 2013, pp. 52-59

[8] B. W. Boehm, et al., "Quantative Ev. of Software Quality," 2nd ICSE, 1976, pp. 596-605.

[9] J. A. McCall, et al., "Factors in Software Quality," 1977.

[10] K, Esaki, Y. Ichinose and S. Yamada, "Statistical Analysis of Process Monitoring Data for Software Process Improvement and Its Application," American Journal of Operations Research, Vol. 3, No. 1A, 2012, pp. 43-50. doi:10.4236/ajor.2012.21005

[11] K. Esaki, "Verification of Quality Requirement Method," American Journal of Operations Research, Vol. 2, No. 1, 2013, pp. 70-79. doi:10.4236/ajor.2013.31006

[12] Kakaku.com (http://www.kakaku.com). 